\title{
The Effect of Strain Rate on Abnormal Grain Growth of P/M Nickel-base Superalloy
}

\author{
Shuang Fang ${ }^{\mathrm{a}}$, Yunpeng Dong ${ }^{\mathrm{b}}$, ShuyunWang ${ }^{\mathrm{c}}$ \\ Beijing Institute of Aeronautical Materials, Beijing, 100095, China
}

\begin{abstract}
The samples with a length of $50 \mathrm{~mm}$ and cross section area of $20 \mathrm{~mm} 2$ were machined from extruded $\mathbf{P} / \mathbf{M}$ Nickel-base superalloy billet and the isothermal deformation tests were carried out at constant strain rate in a vacuum environment using the Thermecmastor. All the samples were deformed to a true strain of $\mathbf{1 . 0 4}$ at deformation temperature $1070^{\circ} \mathrm{C}$ and strain rate $0.001 \mathrm{~s}-1 \sim 0.1 \mathrm{~s}-1$ respectively. The result is the deformation strain rate determine the position and domain of AGG. The aggregation of small grain boundary of all points has certain evolution for different strain rate and the AGG regions of all samples has relative higher grain boundary energy. The high percentage of low energy and low percentage of high migration of CSL boundaries may lead to AGG. The gradient and fluctuation of CSL boundaries in micro region may be comtribut the AGG.
\end{abstract}

Keywords-ni-base superalloy; strain rate; abnormal grain growth; EBSD.

\section{INTRODUCTION}

Abnormal grain growth (AGG) is a discontinuous phenomenon wherein one or more abnormal grains grow rapidly in a uniform microstructure of much smaller surrounding grains [1-3]. AGG, also referred to as secondary recrystallization [4], typically results in microstructures of bimodal grain sizes, containing a small number of very large grains called abnormal grains. AGG is a growth behavior of single grain, so the grain has some advantage to grow rapidly. Lee[4-5] study the grain boundary structure of abnormal grain and find the faced grain boundary is the key factor for the AGG. But the TEM image only can offer micro zone and can not calculate the grain boundary energy and migration rate. Gao[6] calculate the grain boundary energy by Monte Carlo, but the evolution of grain boundary energy following different deformation parameter is not known clearly. In different deformation parameter, Lee[7] find the diffusion compensated strain rate is more important and GE Aviation obtain the same conclusion.

Electron backscatter diffraction (EBSD) in conjunction with scanning electron microscopy (SEM) is a practical technique for measuring crystal orientation. By using a commercial apparat ures for EBSD measurements, it is possible to measure the crystal orientations, for example, grain boundary structure, grain boundary energy, misorientation and grain orientation, of more than 200 points per second by scanning the surface of samples and to obtain mapping data of crystal orientations without difficulty. In present study, the EBSD was carried out in order to investigate the microstructural changes that took place due to different strain rate.

The alloy of interest in this study is a powder metallurgy turbine disk alloy developed by Beijing Institute of Aeronautical Materials named FGH4096, which is similar to the Rene 88DT produced by GE Aviation[8-9]. In the present study, the Nickel-base superalloy samples were prepared by the isothermal forging in different strain rates. The microstructure characterization of the samples was investigated.

\section{EXPERIMENTAL}

The samples with a length of $50 \mathrm{~mm}$ and cross section area of $20 \mathrm{~mm} 2$ were machined from extruded $\mathrm{P} / \mathrm{M}$ Nickel-base superalloy billet according to Figure 1. The average chemical composition of this material was similar to the Rene 88DT. The isothermal deformation tests were carried out at constant strain rate in a vacuum environment using the Thermecmastor (Fuji Electronic Industrial Co., Japan) with a capacity of 30 ton compressive force. Glass powder was filled into each end of the samples as a lubricant to decrease friction on the interface, and to reduce nonuniform deformation during compression. The samples were induction heated to deformation temperature and held for $5 \mathrm{~min}$ at deformation temperature before isothermal deformation. Helium gas quenching was immediately followed by within $10 \mathrm{~s}$ after isothermal deformation to preserve the hot deformed microstructures.

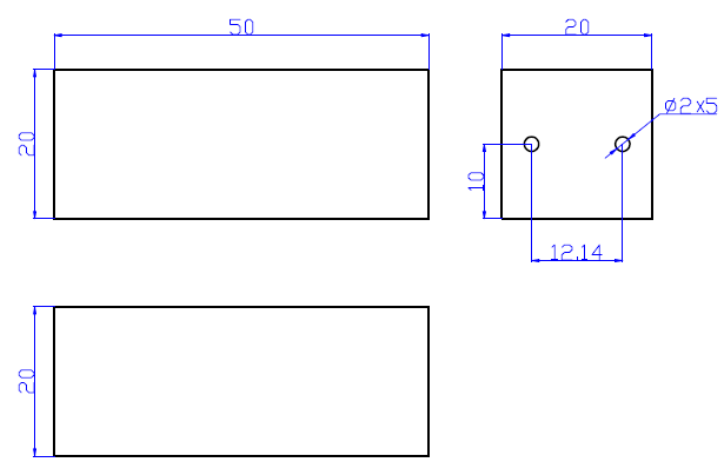

Figure 1. Extruded P/M Nickel-base superalloy alloy samples

All samples were deformed to a true strain of 1.04 at deformation temperature $1070^{\circ} \mathrm{C}$ and strain rate $0.001 \mathrm{~s}-1 \sim 0.1 \mathrm{~s}-1$ respectively. The effective strain map of 
deformed sample was obtained from DEFORM-3D as shown in Figure 2. As isothermal deformed samples were annealed for $2 \mathrm{~h}$ at $1150^{\circ} \mathrm{C}$ for secondary recrystallization.

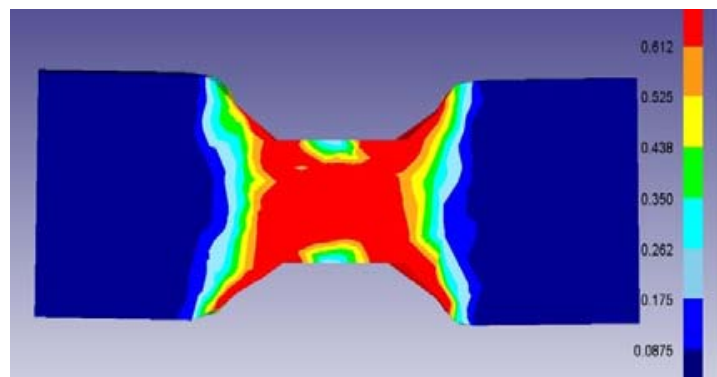

Figure 2. The effective strain map of isothermal deformed sample

\section{RESUlTS AND DisCUSSION}

Table 1 lists all the cross sections of samples after isothermal deformation and heat treatment at $1150^{\circ} \mathrm{C}$. The position of AGG regions of all samples were different following changing of deformation temperatures and deformation strain rate. By $\mathrm{OM}$ observation, the most serious AGG regions move to the low strain level and the AGG domain increase when the deformation strain rate increase as shown in Figure 3.

When the strain rate is the lowest, the AGG region is in the $12 \sim 14 \mathrm{~mm}$ from the right center of sample, and the largest grain size is in the position of $12.8 \mathrm{~mm}$. When the strain rate is $0.01 \mathrm{~s}-1$, the AGG region is in the $12 \sim 16 \mathrm{~mm}$ from the right center of sample, and the largest grain size is in the position of $14.4 \mathrm{~mm}$. When the strain rate is the fast, the AGG region is in the $10 \sim 16 \mathrm{~mm}$ from the right center of sample, and the largest grain size is in the position of $15.2 \mathrm{~mm}$. So the deformation strain rate determine the position and domain of AGG.

TABLE I. THE CROSS SECTION OF ALL SAMPLES AFTER ISOTHERMAL DEFORMATION AT $1070^{\circ} \mathrm{C}$ AND HEAT TREATMENT AT $1150^{\circ} \mathrm{C}$

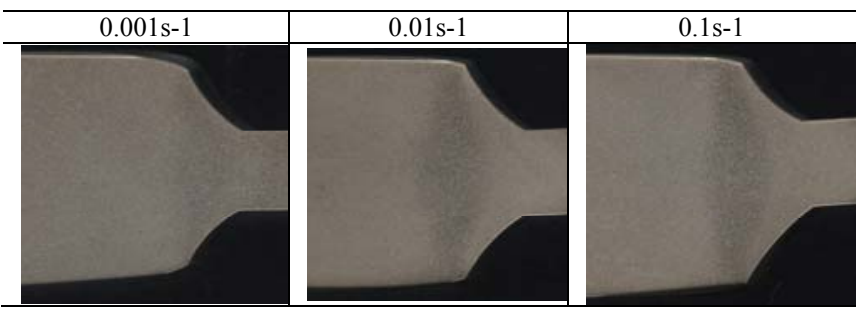

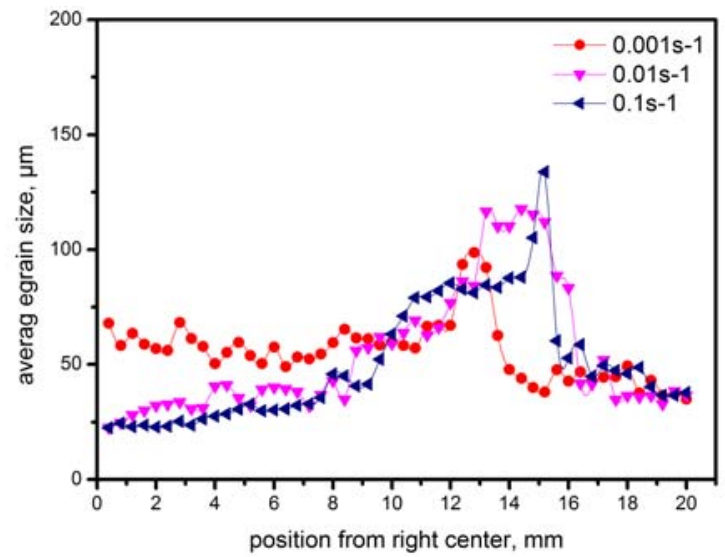

Figure 3. The average grain size of all samples in Table 1

The eight points of each sample, which lie in the $4 \mathrm{~mm}$, $10 \mathrm{~mm}, 12 \mathrm{~mm}, 13 \mathrm{~mm}, 14 \mathrm{~mm}, 15 \mathrm{~mm}, 16 \mathrm{~mm}$ and $20 \mathrm{~mm}$ from the right center of sample, were choosed. The microstructure of deformed samples were analysised by EBSD for the purpose of reason of AGG after heat treatment at $1150^{\circ} \mathrm{C}$.

Small grain boundary energy is related to revolution axis. Rollett, Yang and Mullins measure the average relative grain boundary energy of the small grain boundary of FCC crystal [10-11]. The result of measurement is the relative grain boundary energy of revolution axis [001] is the biggest and the revolution axis [111] is the smallest. Table 2 lists the small grain boundary distribution inage of all points before heat treatment at $1150^{\circ} \mathrm{C}$. It can be seen that the small grain boundary of some points have the aggregation in the revolution axis [101] and [001], which denote this point has higher grain boundary energy. When the strain rate is $0.001 \mathrm{~s}-1$, the small grain boundary has the aggregation in the revolution axis [101] in $10 \mathrm{~mm}$ and $13 \mathrm{~mm}$, where is the most serious AGG. When the strain rate is $0.01 \mathrm{~s}-1$, the small grain boundary has the aggregation in the revolution axis [001] in $14 \mathrm{~mm}$, where also is the most serious AGG. When the strain rate is $0.1 \mathrm{~s}-1$, the small grain boundary has the aggregation in the revolution axis [001] and [101] in $14 \mathrm{~mm}$ and $16 \mathrm{~mm}$, where also is the most serious AGG. The other points of all samples has relative uniform distribution of samll grain boundary. 
TABLE II. SMALL GRAIN BOUNDARY DISTRIBUTION INAGE OF ALL SAMPLES

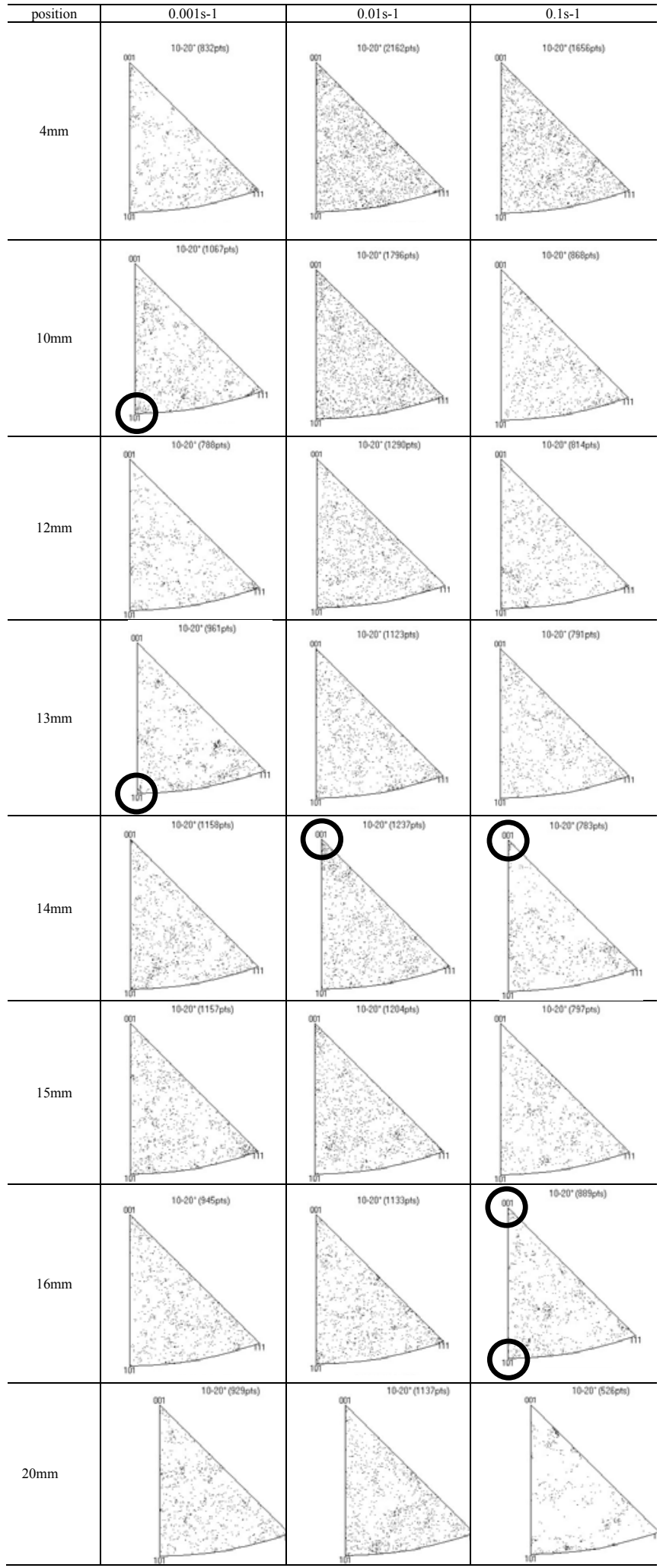

So the aggregation of small grain boundary of all points has certain evolution for different strain rate and the AGG regions of all samples has relative higher grain boundary energy. The relative higher grain boundary energy may be come from dislocation. But the dislocation is or not be used to recrystallization nucleate, which will be studied later.

Large grain boundary energy is also related to revolution axis and remarked by the CSL grain boundary. Brons[10] studied the relation of CSL boundaries with AGG, and finded that the onset of abnormal grain growth resulted in no significant reduction of low-angle boundaries but increases in the 3, 5, 7, 9 and 11 boundary fractions and a texture evolution from $\{101\}$ to $\{001\}$. The

3 and 9 boundaries peaked together during the abnormal grain growth stage and may be contributed to AGG. In this study, the percentage of 5, 9 and 11 with low grain boundary energy and percentage of 7, 13 and 17 with high grain boundary migration were calculated by EBSD, as shown Figure 4.
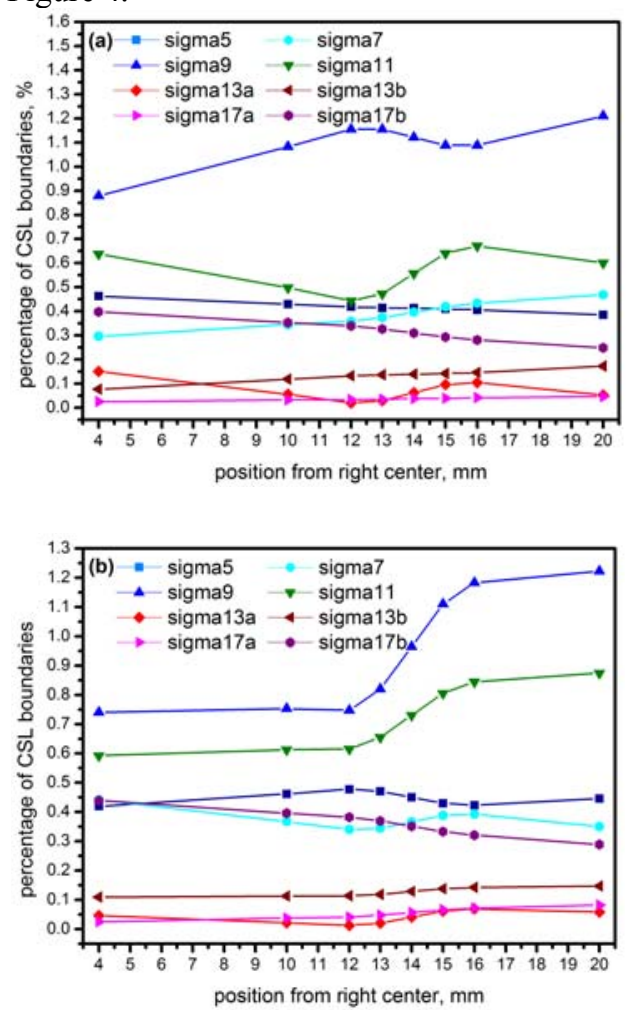


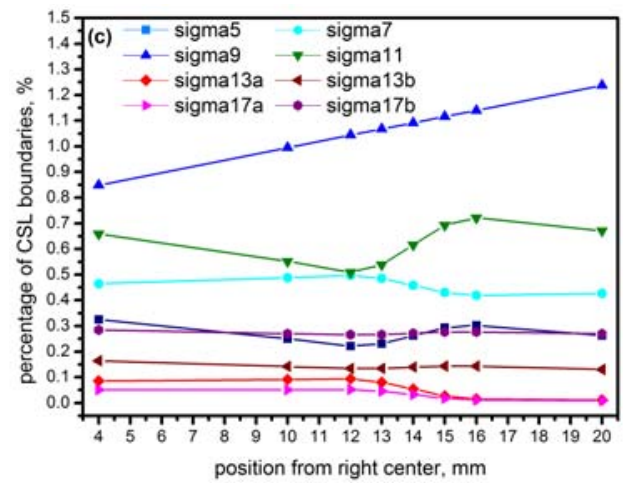

Figure 4. Percentage of CSL boundaries of all samples (a) $1070^{\circ} \mathrm{C}, 0.001 \mathrm{~s}-1$; (b) $1070^{\circ} \mathrm{C}, 0.01 \mathrm{~s}-1$; (c) $1070^{\circ} \mathrm{C}, 0.1 \mathrm{~s}-1$

It can be seen from Figure 4 that the 5, 9 and 11 exist fluctuation in the AGG regions in different strain rate. And in the most serious AGG regions, the percentage of 5 ,

9 and 11 has the extreme value. In the position of $4 \mathrm{~mm}$ and $10 \mathrm{~mm}$, the percentage of 5,9 and 11 has no obvious change, although the strain level is different. In the position of $12 \mathrm{~mm}$, the tendency of curve changes and alters gentleness from the the position of $16 \mathrm{~mm}$. So the AGG regions is related to the gradient of 5,9 and 11 and the higher gradient will lead to more serious AGG. Because the

5, 9 and 11 have the low energy, the change of which will lead to non-homogeneous of microstructure.

The percentage of 7, 13 and 17 also have the same evolution to 5,9 and 11 . The migration is related to the release of dislocation, the fluctuation of may influence the dislocation density in micro region and recrystallization nucleation. So the high percentage of low energy and low percentage of high migration of CSL boundaries may lead to AGG. The gradient and fluctuation of CSL boundaries in micro region may be comtribut the $\mathrm{AGG}$.

\section{CONCLUSIONS}

A. The deformation strain rate determine the position and domain of AGG.

B. The aggregation of small grain boundary of all points has certain evolution for different strain rate and the AGG regions of all samples has relative higher grain boundary energy.

C. The high percentage of low energy and low percentage of high migration of CSL boundaries may lead to AGG. The gradient and fluctuation of CSL boundaries in micro region may be comtribut the AGG.

\section{REFERENCE}

[1] Blankenship. Recrystallization and grain growth in strain gradient samples [J]. Scripta Metallurgica et Materialia, 1994, 31: 647-652.

[2] Rajmohan N, Szpunar J A. An analytical method for characterizing grain boundaries abound growing goss grains during secondary recrystallization [J]. Scripta Materialia, 2001, 44: 2387-2392.

[3] Park J Y, Szpunar J A. Influence of the primary recrystallization texture on abnormal grain growth of goss grains in grain oriented electrical steel [J]. Materials Science Forum, 2002, 408-412 (1): 821-826.

[4] Lee S B, Yoon D Y, Henry M F. Abnormal grain growth and grain boundary faceting in a model Ni-base superalloy [J]. Acta materialia, 2000, 48: 3071-3080.

[5] Lee S B, Sigle W, Kurtz W, Ruhle M. Temperature dependence of faceting in 5(310)[001] grain boundary of $\mathrm{SrTiO} 3[\mathrm{~J}]$. Acta materialia, 2003, 51: 975-981.

[6] Gao Y J, Jin X, Su Y Y, Huang C G, Wei C Y, Monte Carlo simulation of abnormal grain growth [J]. Journal of Guangxi University Nature Science Edition. 2009, 34 (2) : 220-225.

[7] Lee J H, Paik K W, Park L J, Kim Y G. The effect of high temperature deformation conditions on the secondary recrystallization of MA754 plate [J]. Scripta Materialia. 1998, 38 (5) : 789-794

[8] Ning Y Q, Yao Z K, Fu M W, Guo H Z. Recrystallization of the hot isostatic pressed nickel-base superalloy FGH4096: I. Microstructure and mechanism $[\mathrm{J}]$. Materials Science and Engineering A, 2011, 528: 8065-8070.

[9] Ning Y Q, Fu M W, Yao W. Recrystallization of the hot isostatic pressed nickel-base superalloy FGH4096: II. Characterization and application [J]. Materials Science and Engineering A, 2012, 539: 101-106.

[10] Brons J G, Thompson G B. A comparison of grain boundary evolution during grain growth in fcc metals [J]. Acta Materialia. 2013, $613936-3944$. 